\title{
Relato da Utilização de uma Metodologia de Trabalho para o Ensino de Ciência da Computação no Ensino Médio
}

\author{
Pasqueline Dantas Scaico, Emilayne Feitosa Corlett, Luiz Fernando Paiva, \\ Ewerton Henning Souto Raposo, Yugo Alencar ${ }^{1}$
}

\author{
Centro de Ciências Aplicadas e Educação - Universidade Federal da Paraíba (UFPB) - Rua da Mangueira, s/n - CEP 58.297-000 - \\ Rio Tinto - PB - Brasil \\ \{pasqueline, emilayne.corlett, luiz.fernando, ewerton.raposo, \\ yugo.alencar) ddce.ufpb.br
}

\begin{abstract}
This paper reports the experience of a Computer Science course with activities that are promoting the exploration of the teaching of computing in public high-schools. The process used to establish a constant set of activities is reported, as well as the first positive effects of this work to school.
\end{abstract}

Resumo. Este trabalho registra a experiência de alunos de um curso de Licenciatura em Computação com atividades que estão promovendo o ensino de Computação em escolas públicas. Pode-se observar que a metodologia de trabalho utilizada para sistematizar as ações do projeto é um resultado que pode ser utilizado por aqueles que estejam interessados em levar o tema para espaços escolares. Também faz parte do relato os primeiros reflexos concretos do trabalho.

\section{Introdução}

A educação em Ciência da Computação é um fator pouco explorado na educação básica no Brasil. Em função disso, muitos estudantes possuem ideias incorretas e também, atitudes negativas sobre a área, percebendo como chatas e entediantes as carreiras neste campo. Isso pode ser uma das causas da diminuição cada vez mais acentuada na procura pelos cursos de formação superior (G1 2010).

Neste contexto, diversos fatores apontam a relevância de ensinar Computação no ensino médio. Em primeiro lugar, este tipo de educação aproxima os estudantes do tema e gera uma influência significante na escolha das suas carreiras, que por vezes é realizada com base em informações imprecisas. Além do mais, o contato com a Computação permite o desenvolvimento de diversas capacidades, uteis para qualquer atividade profissional, como é o caso do aprendizado e a aplicação de técnicas para resolver problemas que são usadas na Computação, o contato com a abstração de conceitos e o uso de metáforas, e inúmeras competências decorrentes da fluência no uso das tecnologias.

$\mathrm{Na}$ tentativa de engajar os estudantes e fazê-los conhecer mais sobre a CC, muitos projetos têm procurado esclarecer os seus conceitos fundamentais, através de atividades que possam entreter e desafiar. Alguns países têm conseguido implantar um 
currículo mínimo nas escolas, conforme cita Ragonis (2007). Nos Estados Unidos, por exemplo, muitas organizações como a CSTA (Computer Science Teachers Association) - apoiada pela ACM (Association for Computing Machinery) e pelo Google, a ISTE (International Society for Technology in Education) e a NAEP (National Association for Educational Progress) contribuem com modelos de currículos, padrões e guias para estabelecer o ensino de Computação nas escolas (Bell 2010).

No Brasil, a Sociedade Brasileira de Computação (SBC), através da sua Comissão de Especialistas de Ensino de Computação e Informática e do GT3 (Grupo de Trabalho de Licenciatura em Computação), tem fomentado as discussões sobre a importância de introduzir o pensamento computacional e algorítmico nas escolas de ensino médio, para que se possa desenvolver competências e fomentar o interesse pela área, aumentando o número de profissionais no país (Pereira Junior et al. 2005).

Este trabalho registra a experiência de alunos da Licenciatura em Computação na Universidade X com atividades de extensão que estão promovendo a exploração do ensino de Computação em escolas públicas. Desde o início do projeto, mais de 200 alunos já tiveram oportunidade de aprender conceitos básicos sobre a Computação. Dois objetivos principais nortearam o projeto: fortalecer a formação dos estudantes da licenciatura e estabelecer um diálogo na escola sobre a Ciência da Computação e as suas profissões. Este artigo apresenta um relato de experiências resultantes de uma metodologia de trabalho que tem possibilitado envolver sistematicamente estudantes de uma escola pública de ensino médio. Já é possível perceber que o projeto tem sido capaz de influenciar positivamente a cultura dos estudantes, em especial dos estudantes do $3^{\circ}$ ano.

O trabalho está organizado da seguinte maneira. Na Seção 2 são apresentados alguns trabalhos que têm explorado o pensamento computacional no ensino médio. A Seção 3 apresenta a motivação para o projeto, além da metodologia de trabalho utilizada. Na Seção 4 são apresentados maiores detalhes sobre a principal atividade do grupo, que combinou diferentes ações para tratar do tema CC. Na Seção 5 são apresentados alguns resultados provenientes de uma avaliação técnica realizada com os alunos e que visou identificar o conhecimento que fora absorvido pelos participantes, bem como as atividades que ofereciam maior grau de dificuldade de execução para eles. Nas Seções 6 e 7 são registrados alguns resultados preliminares e as considerações finais, respectivamente.

\section{Trabalhos relacionados: Pensamento Computacional e algorítmico}

O interesse em ensinar a Computação na educação básica é um tema que vem sendo tratado em vários locais no mundo. Em alguns países já se utiliza um currículo mínimo para o ensino de CC, é o que acontece em Israel (Gal-Ezer 1999), no Canadá (MEO 2008) e nos Estados Unidos, onde o modelo de currículo investe no ensino de conteúdos que explorem a chamada Educação Imperativa, na qual mais importante do que aprender temas ligados às tecnologias está a capacidade de desenvolver o pensamento computacional (CSTA 2005).

Entretanto, face às dificuldades de introduzir a $\mathrm{CC}$ como uma disciplina nos currículos escolares, muitos trabalhos têm inserido este tema através de atividades extracurriculares. O trabalho de Futschek e Moschitz (2011) utiliza um cenário lúdico chamado de Tim the Train para trabalhar o conceito de abstração com estudantes em 
idade escolar que estão aprendendo programação. Essa abordagem orientada a cenários proporciona a oportunidade de desenvolver capacidades uteis para resolver problemas mais avançados da Ciência da Computação. No Brasil, algumas ações têm explorado o ensino de lógica da programação, visando a preparação dos estudantes para a Brasileira de Computação (OBI) nas escolas. Um exemplo são os trabalhos de Garcia (2008) e Barros (2009).

Um dos projetos mais conhecidos mundialmente para favorecer o trabalho com o pensamento computacional são as atividades desenvolvidas por Tim Bell e Ian H. Witten, denominadas como Computação Desplugada, que consistem na exploração dos fundamentos da Ciência da Computação sem a necessidade do uso de computadores. Pela facilidade de sua produção, as atividades se tornam viáveis em lugares remotos ou de pouca infraestrutura (Bell 2007). Há inúmeros relatos no mundo de como essas atividades têm sido aplicadas. No Brasil, Sousa et al (2010) apresenta um relato da aplicação de tais atividades em quatro escolas no estado da Bahia. Assim como, os trabalhos de Costa et al (2012) e França (2012) mostram a realização dessas atividades em espaços escolares através de estudantes da Licenciatura em Computação. Tais trabalhos são muito importantes porque relatam essas experiências e disseminam a importância da introdução de conceitos de CC. Todavia, há de se mencionar questões que precisam ser evidenciadas:

1) Quais são os efeitos que a introdução de atividades dessa natureza provocam nas escolas?

2) Como a visão e a atitude dos estudantes são influenciadas após as experiências?

3) Como pode ser descrita uma metodologia do trabalho que sistematize tais ações nas escolas?

Levando isso em consideração, o projeto procurou contribuir neste sentido. $\mathrm{O}$ trabalho apresenta, na forma de um relato, as ações desenvolvidas em um projeto que têm conseguido envolver os alunos de uma escola pública de ensino médio há mais de um ano com atividades que tratam de Computação. O leitor poderá observar como foi conduzido o processo para a entrada do tema Ciência da Computação em uma escola que sequer utilizava seu pequeno laboratório de informática e dos efeitos que foram gerados na escola.

\section{Motivação e descrição da metodologia utilizada}

Uma inquietação recorrente no curso de Licenciatura em Computação da Universidade Federal da Paraíba era a organização de espaços pedagógicos para que os estudantes pudessem experimentar a docência no ensino da Computação, enquanto Ciência. Experiências já haviam acontecido em algumas escolas, contudo, estavam bastante concentradas no uso de tecnologias educacionais como apoio às disciplinas do currículo escolar. Sentia-se que a formação dos estudantes da licenciatura não estava sendo plena. Por outro lado, a procura pelos cursos na área de Computação estava diminuindo cada vez mais.

Assim, com o objetivo de estabelecer novos espaços de docência para os licenciandos e de levar novos conhecimentos para os estudantes do ensino médio, elaborou-se uma estratégia a partir de um projeto de extensão que pudesse introduzir o tema Ciência da Computação através de atividades complementares, que seriam 
ofertadas no contra horário das aulas. $\mathrm{O}$ projeto teve início com a escolha de uma pública que possuía cerca de 600 alunos matriculados no ensino médio e dispunha de um laboratório pequeno de informática com dez máquinas.

A metodologia de trabalho utilizada organizou o esforço em quatro etapas: 1) identificação do perfil dos estudantes; 2) divulgação das atividades na escola; 3) realização de múltiplas atividades, visando progressivamente envolver os estudantes e avaliar o processo e 4) estabelecimento de métricas que pudessem apontar reflexos do projeto com os estudantes do $3^{\circ}$ ano.

A primeira etapa da metodologia foi realizada através de um questionário aplicado com 450 alunos para que fosse possível identificar o seu perfil sociocultural, as informações que tinham sobre a área e os seus interesses com tecnologia. Dos participantes da pesquisa, $40 \%$ dos alunos cursavam o $1^{\circ}$ ano, $33 \%$ o $2^{\circ}$ ano e $27 \%$ o $3^{\circ}$ ano. Os dados revelaram que apenas $25 \%$ dos entrevistados possuíam computador em casa, todavia, mais de $80 \%$ já tinham utilizado a Internet. Quando perguntados sobre o local de acesso à Internet, $75 \%$ disse utilizar as lan houses da cidade. Apenas $2 \%$ apontaram a escola como um local possível para isso. Ao serem perguntados sobre o seu nível de conhecimento em informática, $56 \%$ afirmou conhecer pouco, $2 \%$ disse ter um nível avançado e os demais, um nível intermediário. $\mathrm{O}$ estudo também mostrou que os alunos não possuíam qualquer informação concisa sobre as profissões na área de Computação e que o laboratório nunca era utilizado como espaço das aulas dos professores. Também foram investigados os interesses dos estudantes em relação à tecnologia. A maioria dos estudantes apontou interesses relacionados às redes sociais e jogos. Este foi o ponto de partida para o início das demais atividades do projeto.

A segunda etapa se referia à divulgação das atividades e ocorreu através de entrega de material impresso e de visitas da equipe do projeto às salas de aula das turmas do ensino médio, público-alvo do projeto. Em função da necessidade de detalhar bem a terceira etapa da metodologia, que se refere às múltiplas atividades que introduziram temas da CC, dedicou-se a Seção 4 deste documento para esse detalhamento.

\section{Descrição das múltiplas ações para o ensino de CC}

Sabendo-se da necessidade de estabelecer diferentes atividades para despertar a curiosidade dos alunos e o seu envolvimento, foram preparados três grupos de ações que se desenvolveram ao longo de oito meses. As ações iniciaram com minicursos de curta duração, depois através de uma competição de equipes e finalmente, com cursos de maior duração na área de introdução à programação. Os detalhes de cada atividade podem ser vistos nas subseções que seguem.

\subsection{Minicursos}

Com base nos interesses dos alunos, quatro pequenos cursos (com duração de 4h) foram produzidos e divulgados na escola. Os temas abordados tratavam da história da computação, arquitetura dos computadores, tipos de redes e criação de conteúdo na web. Os minicursos aconteciam durante os sábados, de dois em dois, em horários coincidentes, e nas dependências da universidade. Esta foi uma forma que o grupo enxergou de despertar a curiosidade dos alunos e aproximá-los das atividades. 
Cinquenta alunos, em média, realizaram pelo menos um dos cursos oferecidos. Nesta fase do projeto, conseguiu-se reunir cerca de 120 estudantes do ensino médio. Este contato inicial estabeleceu um canal para que novas atividades pudessem ser aplicadas e assim, iniciou-se a segunda etapa do projeto, que foi a organização de uma gincana de grupo. Durante alguns dias a equipe do projeto visitou a escola para divulgar a gincana e estimular os alunos a formar suas equipes para competição.

A gincana foi organizada em duas etapas, a primeira delas aconteceu na própria universidade e a segunda, na escola. Os detalhes da execução das atividades, bem como, a sua avaliação e os seus desdobramentos estão relatados ao longo do artigo.

\subsection{A gincana desplugada}

O pensamento computacional é bastante estimulado nas atividades desenvolvidas por Tim Bell no livro "Computer Science Unplugged" (CSU), que tem o intuito de ensinar fundamentos sobre a Ciência da Computação sem o uso do computador (Bell 2007). Este método de ensino é interessante por criar situações que facilitem o contato de estudantes com os conceitos básicos da Computação, explorar questões relacionadas ao trabalho em equipe, a resolução de problemas e a criatividade.

As atividades põem em prática técnicas utilizadas na Computação para a resolução de problemas, a exemplo do uso de metáforas, a abstração de conceitos e o método de divisão e conquista. A Gincana Desplugada utilizou oito atividades propostas no livro e seus roteiros estão disponíveis no endereço web http://www2.ccae.ufpb.br/pibid. Como pode se observar pela Tabela 1, uma quantidade significativa de alunos participou das atividades.

Tabela 1. Número de execuções das atividades e seus participantes

\begin{tabular}{l|c|ccc}
\hline \multicolumn{1}{c}{ Atividade } & Participantes & \multicolumn{2}{c}{ Número de execuções/local } \\
\cline { 3 - 5 } & & Universidade & Escola & Total \\
\hline Contando os Pontos - Números Binários & 80 & 1 & 5 & $\mathbf{6}$ \\
Você Pode Repetir - Compreensão de Texto & 70 & 1 & 4 & $\mathbf{5}$ \\
A mágica de Virar as Cartas - Detecção de Textos & 20 & 1 & 1 & $\mathbf{2}$ \\
Batalha Naval - Algoritmo de Busca & 45 & 1 & 1 & $\mathbf{2}$ \\
Seja o Mais Rápido - Redes de Ordenação & 50 & 3 & 1 & $\mathbf{4}$ \\
O Jogo da Laranja -Bloqueios nas Redes & 70 & 3 & 4 & $\mathbf{7}$ \\
Seguindo Instruções - Linguagens da Programação & 50 & 1 & 2 & $\mathbf{3}$ \\
O mais leve o mais pesado - ordenação & 30 & 3 & 0 & $\mathbf{3}$ \\
\hline
\end{tabular}

A última etapa da metodologia de trabalho correspondeu à oferta de um curso introdutório de programação com a linguagem Scratch, que permitiu o primeiro contato de muitos alunos com o raciocínio lógico e matemático aplicado à Computação.

\subsection{Aprendendo a programar com o Scratch}

Para a terceira etapa do projeto, a equipe planejou a realização de um curso introdutório de programação. Inicialmente, Python havia sido escolhida como linguagem de programação para o módulo básico. Entretanto, após a conclusão da gincana, foi possível identificar as potencialidades dos alunos e as fragilidades do 
ensino oferecido pela escola. Havia grande deficiência nos conteúdos da área de Matemática. Assim, realizou-se um estudo sobre outra linguagem que pudesse ser mais adequada. Chegou-se a conclusão que o $\operatorname{Scratch}^{1}$, uma linguagem de programação criada pelo MIT, possuía uma sintaxe fácil, baseada em blocos de montar, em que seria possível criar jogos e animações simples. Outra vantagem da linguagem é que seria possível introduzir grande parte das estruturas básicas de uma linguagem de programação de uma maneira agradável para os iniciantes.

$\mathrm{O}$ curso estimulou o ensino baseada no conceito de design, que enfatiza a concepção (criar e não apenas utilizar ou interagir), a personalização (criar algo que é pessoalmente significativo e relevante), a colaboração (trabalhar com outras pessoas no processo criativo) e a reflexão (rever e repensar as práticas criativas de cada um). A aprendizagem baseada no conceito de design é particularmente adequada para a computação criativa, que apóia o desenvolvimento das ligações pessoais dos jovens com a computação, com base na criatividade, imaginação e interesses.

O curso básico teve carga horária de $20 \mathrm{~h}$ e iniciou em março de 2012 com quatro turmas, que contabilizaram 25 alunos, que assistiam aulas semanais, no laboratório da escola. Praticamente todos os alunos que participaram da pesquisa e disseram desejar participar do curso, participaram do curso com $75 \%$ de assiduidade. $\mathrm{O}$ planejamento do curso, bem como os projetos utilizados e os roteiros de aula podem ser acessados no endereço web do projeto disponibilizado anteriormente.

\section{Avaliação das atividades desenvolvidas}

Trinta dias após a finalização da segunda etapa do projeto (descritas na Seção 4) foi realizada uma pesquisa de opinião na escola para que se pudessem aferir algumas impressões sobre as atividades. Também foi aplicado um questionário com treze perguntas, algumas delas técnicas, relacionadas aos assuntos de Computação. Os alunos avaliaram, entre outras coisas, o nível de satisfação em relação aos desafios a que foram submetidos. Tentou-se avaliar também que informações técnicas os estudantes haviam retido.

Quando questionados sobre a importância do projeto (Tabela 2), 100\% dos alunos disseram ser importante conhecer mais sobre os conceitos da Computação, além do que, 90,32\% deles mencionaram que as atividades desenvolvidas despertaram mais o interesse pela área. Quando questionados se gostariam de fazer um curso mais prolongado na escola sobre programação, $83,87 \%$ dos alunos responderam positivamente.

Tabela 2. Resultado do interesse dos alunos e compreensão das atividades

\begin{tabular}{l|cc}
\hline \multicolumn{1}{c|}{ Perguntas } & \multicolumn{2}{c}{ Respostas } \\
\cline { 2 - 3 } & Sim (\%) & Não (\%) \\
\hline Você acha importante conhecer conceitos da computação? & 100,0 & 0,0 \\
O contato com as atividade fez você se interessar mais pela área de computação? & 90,3 & 9,6 \\
& 83,8 & 16,1 \\
\hline
\end{tabular}

\footnotetext{
${ }^{1}$ http://scratch.mit.edu/
} 
Em relação ao nível de satisfação dos alunos, observou-se que a maioria teve uma impressão positiva da gincana. Dentre as atividades, observou-se que o desafio "O jogo da laranja" obteve maior aceitação, principalmente, por ser uma atividade desafiadora (Figura 1).
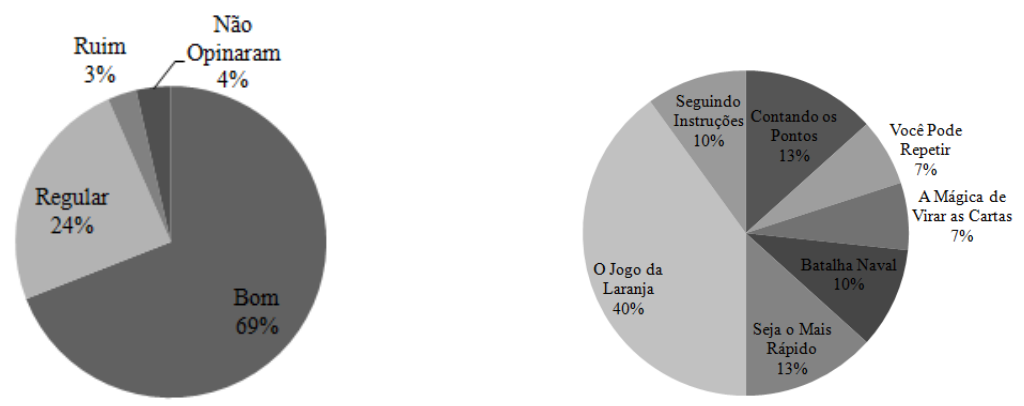

Figura 1. (a) Satisfação com as atividades (b) Aceitação de cada desafio

Em relação ao nível de dificuldade das atividades, observa-se pela Figura 2 que o desafio "Seja o Mais Rápido" foi considerado de maior dificuldade de resolução, em contra posição, o desafio "Batalha Naval" foi considerado pela maioria uma atividade fácil de solucionar.

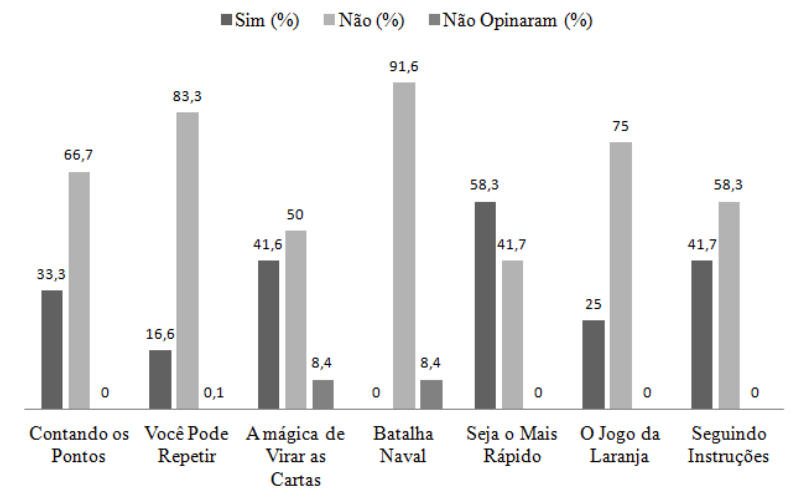

Figura 2. Nível de dificuldade dos desafios

Percebeu-se que algumas dificuldades que os participantes possuíam estavam relacionadas ao trabalho em equipe, a negociação de estratégias e a capacidade de expressar ideias. Percebeu-se também que algumas atividades deveriam acomodar alguns ajustes para que se tornassem mais pedagógicas. A equipe trouxe contribuições para diversas atividades propostas no livro, as quais podem ser visualizadas no endereço web http://(omitido por questões de confidencialidade). No questionário estavam presentes algumas questões técnicas (Figura 3). O objetivo de inclui-las foi avaliar quanto de conhecimento técnico havia sido retido pelos estudantes. 


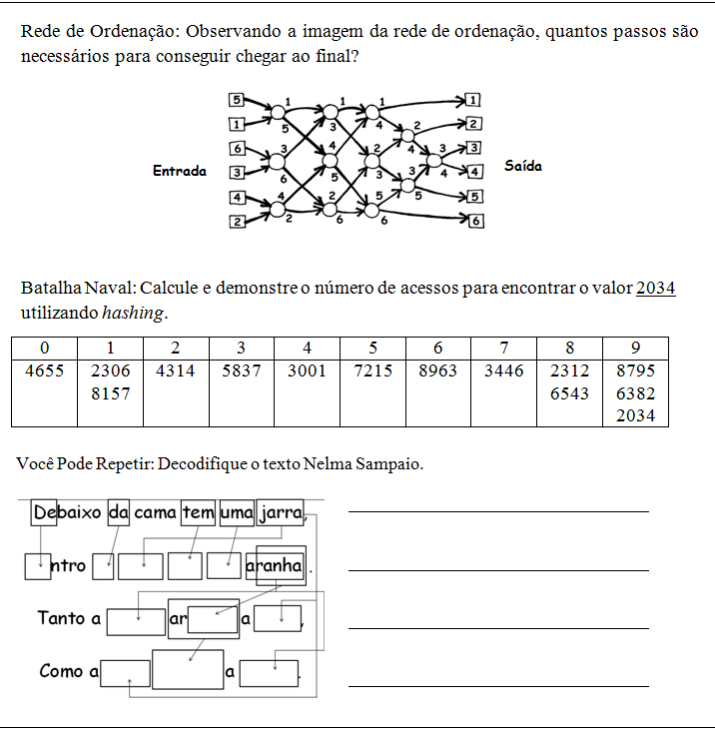

Figura 3. Perguntas técnicas

Ao correlacionar a quantidade de acertos para as perguntas com a análise da dificuldade relatada pelos alunos (Figura 4), percebeu-se, por exemplo, que na questão relacionada ao desafio "Você pode Repetir", considerado fácil pela maioria, 83,9\% dos alunos acertou a resposta, enquanto que a questão relacionada ao desafio "Seja o Mais Rápido", considerado difícil, o índice de acerto das respostas atingiu um nível de 90,0\%.

$$
\text { -Erros(\%) } \quad \text { Acertos(\%) }
$$

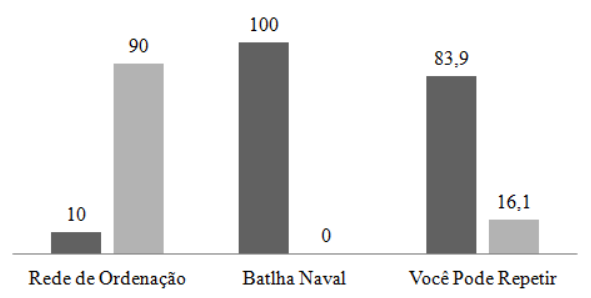

Figura 4. Erros e acertos de questões

O curioso é que, ao analisar o número de acertos para à pergunta relacionada ao desafio "Batalha Naval", considerado fácil, nenhum aluno acertou a resposta.

\section{Resultados preliminares}

Para completar a última etapa da metodologia, a direção da escola foi procurada para que se quantificassem alguns efeitos do projeto. Para estabelecer a métrica, utilizou-se dados referentes à procura e aprovação dos estudantes em processos seletivos para cursos superiores. Em 2010 foram aprovados no Processo Seletivo Seriado (PSS), o vestibular, com entrada para o ano de 2011, apenas 14 alunos da escola. No vestibular de 2011, com entrada em 2012, o número de alunos aprovados passou para 53, o que representou um aumento considerável em relação à procura e ao índice de aprovação do ano anterior. 
Observou-se também o aumento do número de alunos aprovados para a área de Computação (Tabela 3). Vale destacar que dos quatro alunos aprovados para o curso de Licenciatura em Computação, três participaram ao longo do ano das atividades propostas pelo projeto.

Tabela 3. Aprovados PSS 2011/2012 na área de Computação (Pesquisa direta)

\begin{tabular}{l|cc}
\hline \multicolumn{1}{c}{ Cursos } & \multicolumn{2}{c}{ Número de alunos aprovados } \\
\cline { 2 - 3 } & $\mathbf{2 0 1 1}$ & $\mathbf{2 0 1 2}$ \\
\hline Ciência da Computação & 0 & 4 \\
Engenharia da Computação & 0 & 1 \\
Sistemas de Informação & 3 & 1 \\
Total & $\mathbf{3}$ & $\mathbf{6}$ \\
\hline
\end{tabular}

Pode-se dizer que a escola estabelecia uma política frágil de orientação dos alunos sobre as carreiras no ensino superior, assim, os seus alunos não costumavam enxergar a universidade como uma opção disponível. Possivelmente, o aumento dos números se deve à influência que o projeto vem exercendo.

De maneira geral, observa-se que a prática desenvolvida com os alunos das atividades apresentadas, bem como a presença dos universitários na escola despertou maior interesse dos alunos por esses cursos. Segundo Sousa et al (2010), "a inovação educacional por meio da utilização de atividades lúdicas é importante fonte de atração e consolidação de conhecimento, em especial para crianças e jovens em idade escolar".

É importante mencionar que após a execução da gincana, outra escola da região procurou a universidade para que as atividades pudessem ser realizadas com seus alunos. $\mathrm{O}$ interessante é que a iniciativa de convidar a equipe partiu dos próprios alunos dessa escola, que tinham, através de seus colegas, recebido boas indicações sobre as atividades. $\mathrm{O}$ projeto realizou um evento menor na escola em questão, no qual quatro atividades foram apresentadas e mais de trinta alunos participaram.

\section{Considerações finais}

O projeto de extensão descrito neste trabalho foi conduzido por uma equipe formada por oito alunos de Licenciatura em Computação. Pode-se dizer que os resultados alcançados até este momento superaram as expectativas iniciais. Foi possível falar sobre Computação, estimular a capacidade de resolver problemas que os estudantes do ensino médio possuem e, principalmente, mostrar-lhes o ensino superior como uma possibilidade viável para uma formação profissional de qualidade. Todos os alunos que participaram das atividades tiveram a oportunidade de entender mais sobre a Computação, alguns deles já são alunos ingressantes de um curso na área de tecnologia, mais conscientes e informados sobre a formação que escolheram.

Para os universitários, estudantes da licenciatura, esta foi uma experiência valiosa, porque lhes permitiu o amplo exercício da docência, e que expôs a realidade da escola pública. Além do mais, o projeto estabeleceu um espaço de observação, em que se pôde estimular o empreendedorismo nos universitários para que enxerguem os desafios existentes como novas oportunidades. 
A expansão do ensino de Computação nas escolas públicas da região é uma meta do projeto. Espera-se poder utilizar o potencial dos estagiários do curso para isso. Outra meta é desenvolver projetos de pesquisa que avaliem os resultados reais de aprendizagem dos alunos, isto porque se percebeu que muitas atividades precisaram de incrementos para atender melhor seus objetivos iniciais.

A contribuição que este trabalho apresenta é justamente o relato de uma experiência de sucesso, que deve funcionar como um estímulo para que outros cursos, principalmente os de Licenciatura em Computação, assumam sua responsabilidade social de inovar os processos de ensino-aprendizagem, não apenas propondo recursos tecnológicos como jogos ou objetos de aprendizagem, mas novos métodos e técnicas para desenvolver nos estudantes a capacidade de pensar e construir o conhecimento. Além do que, oferece uma possibilidade através de um conjunto de ações que podem abrir um canal de comunicação com a escola, o que consequentemente se reflete em novos espaços de atuação para os alunos da Licenciatura em Computação.

\section{Referências}

Barros, L., Ribeiro, S. P. S., Oeiras, J. (2009) "Projeto de Extensão Universitária para apoio e realização da Olimpíada Brasileira de Informática em Escolas”. In: XXIX Congresso da SBC - XVII WEI, Bento Gonçalves.

Bell, T., Whitten, I., Fellows, M (2007) Computer Science Unplugged. Universidade de Canterbury, Nova Zelândia. Disponível em http://csunplugged.org

Bell T., Andreae P., Robins A. (2010) Computer science in NZ high schools. Procedings 12th Australasian Computing Education Conference (ACE 2010), Brisbane, Australia.

Costa, T. R., Batista, A., Maia, M., Almeida, L. e Farias, A. (2012) “Trabalhando Fundamentos de Computação no Nível Fundamental: experiência de licenciandos em Computação da Universidade Federal da Paraíba". XX Workshop de Educação em Computação (WEI'2012). Curitiba, PR, Brasil.

França, S. R., Silva, W. C. e Amaral, H. J. C. (2012) “Ensino de Ciência da Computação na Educação Básica: Experiências, Desafios e Possibilidades”. XX Workshop de Educação em Computação (WEI'2012). Curitiba, PR, Brasil.

Futschek, G.; Moschitz, J. (2011) "Learning Algorithmic Thinking with Tangible Objects Eases Transition to Computer Programming”. In: ISSEP'11 Proceedings of the 5th international conference on Informatics in Schools: situation, Evolution and Perspectives.

Gal-Ezer, J.; Harel D.; Yehudai, A. (1995) “A High-School Program in Computer Science”. In: Journal Computer. Volume 28 Issue 10.

Garcia, R. E.; Correia, R. C. M.; Shimabukuro, M. H. (2008) "Ensino de Lógica de Programação e Estruturas de Dados para Alunos do Ensino Médio”, In: Anais do XXVIII WEI, CSBC'2008, Belém/PA.

Pereira Júnior, J.; Rapkiewicz, C.E.; Delgado, C.; Xexeo, J.A.M. (2005) "Ensino de Algoritmos e Programação: Uma Experiência no Nível Médio". XIII Workshop de Educação em Computação (WEI'2005). São Leopoldo, RS, Brasil.

Ragonis, N. (2007) Computing Pre-University: Secondary Level Computing Curricula. In Encyclopedia of Computer. Proc. 12th Australasian Computing Education Conference (ACE 2010), Brisbane, Australia 21Science, 4th Edition, Ralston.

Site do G1 (2010) http://www.gp1.com.br/noticias/matematica-e-ciencias-da-computacaotem-alta-taxa-dedesistencia-72501.asp. Acessado em 11/04/2012.

Sousa, R. V. de; Barreto L. P; Andrade, A; Abdalla, D. (2010) "Ensinando e aprendendo conceitos sobre a ciência da computação sem o uso do computador: Computação Unplugged!”. Práticas em Informática na Educação: Minicursos do Congresso Brasileiro de Informática na Educação, vol. 1, Número 1, 2010. 